\title{
SOME RESULTS FROM THE AUTOMATIC PZT \\ AT RICHMOND, FLORIDA
}

\author{
DON R. MONGER \\ Director, NOTSS, Richmond, Florida, U.S.A.
}

\begin{abstract}
Automatic operation of the PZT located at the U.S. Naval Observatory Time Service Substation, Richmond, Florida was initiated February 1, 1970. A comparison of one year's automatic operation with the previous year's operation has shown a significant increase in the number of time and latitude sights obtained.

Based on an improved ventilating system within the PZT, the probable error of a single night's observation has been reduced.
\end{abstract}

Modification of the PZT located at Richmond, Florida, enabling it to operate automatically, was completed in late January 1970 . The modification consisted of mounting a cylindrical box around the PZT rotary and a rain shield immediately beneath the roof of the PZT building. A ventilating system was also installed which forces ambient air to flow through the PZT and the box when the box is closed.

The function of the box is to allow loading of photographic plates into the PZT in the daytime when the box is closed, and to allow the PZT lens an unrestricted view of the sky near the zenith when the box is open. Both the box and its associated ventilating system are controlled by a $24-\mathrm{hr}$ timer. The timer is set to open the box and turn off ventilation approximately $40 \mathrm{~min}$ after sunset and to perform a reverse action $40 \mathrm{~min}$ before sunrise. The rain shield is controlled by a rain detector mounted above the roof of the PZT building. Automatic control of PZT exposures has been accomplished for the past two decades by a variety of devices.

In practice, the PZT is made ready for operation in the afternoon before the close of regular office hours and is left to operate unattended until the beginning of office hours the next day. Operation of the PZT during the course of the observations is monitored by a multichannel chart recorder and can also be monitored by telephone.

Automatic operation of the PZT began on 1 February 1970. During the first year of operation 6841 stars were observed on 297 nights. This may be compared with an average per year for the previous four years of 4118 stars on 242 nights. The significant increase in the number of observing nights per year is the direct result of automatic operation.

The probable errors in time and latitude of a single star observation have been obtained from the residuals with respect to the mean for each night. The results shown in Table I were determined separately for a period of one year before and one year after the start of automatic operations. There is no significant difference, indicating that automation had no effect. Further, within the limits of 0.002 and $0 " 03$, the probable errors are independent of the number of stars observed during the night. 
TABLE I

Probable error of one star

\begin{tabular}{lcr}
\hline Period & Time & Latitude \\
\hline Feb. 1969-Feb. 1970 & \pm 0.0142 & \pm 0.176 \\
Feb. 1970-Feb. 1971 & $\mathbf{0 . 0 1 3 2}$ & $\mathbf{0 . 1 7 6}$
\end{tabular}

The probable errors in time and latitude of one night's observations have also been obtained from observed MINUs adopted values of the clock correction and latitude. The adopted values were obtained by smoothing the observed results at monthly intervals by a fourth power polynomial regression. Each monthly solution included data for a period of 10 days before the beginning and 10 days after the end of the month. The results obtained for the year before automation are shown in Table II, and for the year after automation in Table III. As expected, the probable errors in both tables decrease as the number of stars in the night increase. A comparison of Table II with Table III shows, with one exception, that the probable errors of the

TABLE II

Probable error of one night non-automatic PZT

\begin{tabular}{lrr} 
No. Stars & \multicolumn{1}{c}{ Time } & Latitude \\
\hline $4-9$ & \pm 0.0071 & \\
$10-15$ & 0.0059 & 0.081 \\
$16-21$ & 0.0057 & 0.072 \\
$22-27$ & 0.0056 & 0.063 \\
28 or more & 0.0052 & 0.081
\end{tabular}

TABLE III

Probable error of one night automatic PZT

\begin{tabular}{lrr}
\hline No. Stars & Time & Latitude \\
& & \\
$4-9$ & \pm 0.0066 & \pm 0.086 \\
$10-15$ & 0.0045 & 0.043 \\
$16-21$ & 0.0038 & 0.056 \\
$22-27$ & 0.0029 & 0.045 \\
$28-33$ & 0.0029 & 0.048 \\
33 or more & 0.0037 & 0.047
\end{tabular}

automatic PZT are smaller than the corresponding probable errors of the nonautomatic PZT. The author expected an opposite situation, since the automatic PZT does not discriminate against poor observing conditions. The reduced probable errors of the automatic PZT can be explained by the reduction of temperature differentials existing within and immediately around the PZT rotary. It is therefore important to provide for adequate ventilation of the PZT, particularly in the area of the lens and plate holder. 
Improved efficiency by automatic operation has more than justified the automatic PZT. The extended nightly observing period which the automatic PZT provides permits observing more stars, investigating their catalog errors, and simplifying investigation of constants and instrumental effects. For this purpose, observation of a supplementary list of 80 stars was initiated and has yielded 1957 observations on 126 nights between 30 July 1970 and 1 February 1971.

\section{DISCUSSION}

Wm. Markowitz: It appears that there is little direct advantage in determination of time and latitude by observing many stars per night, e.g., 40 vs 20 . However, automatic operation does permit the observation of many stars during the night, if desired for some purposes, without operator attention. 